\title{
AN ORAL HISTORY PROGRAM ON THE BATTLE OF LTTTLE BIGHORN FROM THE PERSPECTIVE OF THE INDIAN DESCENDANTS
}

\author{
Royal G. Jackson \\ College of Forestry \\ Oregon State University \\ Corvallis
}

\section{Objectives}

The general objective of this research is to develop an oral history program on the Battle of Little Bighorn from the perspective of the Northern Cheyenne Indian descendants of this famous encounter with General George A. Custer and the U.S. 7th Cavalry. The specific objectives are:

1. To complete oral history interviews with no less than 15 informants of the Northern Cheyenne Tribe, who shall be selected by the National Park Service;

2. To transcribe all interviews in the form of typed manuscripts; and

3. To develop a cross-referenced retrieval index system.

An optional objective is to provide training in oral history methodology for personnel identified by the National Park Service who might continue the program

\section{Methods}

In August of 1985 a residence was established in National Park Service quarters at Custer Battlefield National Monument and the research was actively commenced. Several weeks were spent reviewing primary and secondary historical materials in the Monument's reference library, where an office was provided. A preliminary interview format was constructed consisting of more than 50 questions centering on the battle, Plains Indian culture, and the early reservation period. Initial contacts were made with individuals in the Crow and Cheyenne communities and extensive travel to the Northern Cheyenne Reservation (45 miles from the Battlefield) was carried out in order to become familiar with the physical environment as it relates to the Custer battle. Assistance was provided by National Park Service personnel, as well as by individuals at Little Bighorn College on the Crow Reservation and Dull Knife Memorial College on the Cheyenne Reservation. Knowledgeable persons in the private sector were also consulted, i.e., individuals associated with the retail outlets in the immediate environs, such as trading posts and other businesses. The public library in nearby Hardin, Montana was also utilized for contemporary information about the Cheyenne. 
After the initial familiarization period, key informants were sought out in the Indian comrnunity. Particularly helpful was the Park Service's Indian Historian, Mardell Plainfeather, who accompanied the investigator to Lame Deer to make contacts with potential informants. A useful technique in aral history is to locate a local resident who is well known in the community, is interested and knowledgeable in history, and is willing to serve as an intermediary between the investigator and the informants. Such an individual was encountered-Jim King, a descendant of Brave Wolf who was a battle participant-and he agreed to assist in the Project. Mr. King is widely known as the Cheyenne community's unofficial historian; he also has a small collection of historical artifacts, many of which relate to the Battle of the Little Bighorn.

A list of potential informants was gradually developed over the course of numerous meetings. The primary criterion was that the individual had to be a descendant of a participant in the battle. Between September 15th and October 17th, fourteen informants located throughout the Northern Cheyenne Reservation were interviewed. A preliminary interview was always carried out to determine the potential informant's eligibility for the study, his general level of English comprehension and knowledge of the tribe's history, and to set the stage for the subsequent interview.

In August of 1986 the second phase of data collection commenced. As before, a residence was established at Custer Battlefield in National Park Service housing. From August through September the investigator traveled throughout the reservation contacting potential informants; ultimately an additional six interviews were carried out, bringing the total to twenty. The progress of the data collection was much more rapid during the second phase due to the previous background work accomplished.

\section{Progress Toward Objectives}

Objective \#1: To complete oral history interviews with no less than 15 informants of the Northern Cheyenne tribe, was accomplished. The objective for the second phase of the research was to interview an additional three to five informants. Both of these objectives are now accomplished with 20 completed interviews. Objective \#2: The transcription of all interviews is almost completed. Eighteen of 20 interviews have now been completed. Both of the remaining two interviews are presently being transcribed and should be completed before the end of December, 1986. All 18 transcripts have been sent to the informants for review and comment. Postage paid, addressed envelopes have been included to facilitate a response. Objective \#3: The development of a cross-referenced retrieval index system, will be commenced in the near future when the last two interviews are transcribed.

\section{Methodalogical Problems}

The same methodological problems encountered during the first phase of data collection occurred during the second period. Considerable time and effort was expended to identify and locate eligible and willing subjects for the study. 
Previous experience with white researchers and others interested in the Custer story, made it difficult to gain the confidence of potential informants. Many pointed out that whites had been coming to the reservation over the years to interview Indians and "write books and make a lot of money." They felt that the Indians from whom the information was obtained had profited very little, while the writers had received handsome monetary rewards. Almost from the moment of the historic unfolding of events on June 25, 1876 there have been throngs of people coming to the area to get "the real story about Custer." These have included official government commissions, politicians, anthropologists, historians, interested scholars, tourists, casual visitors, and others. Fewer difficulties were encountered during the second data collection period because the investigator immediately offered an informant fee, which accelerated cooperation to a considerable degree.

\section{Preliminary Findings}

The preliminary findings after the second phase of interviewing have not significantly changed from what they were found to be after the first round of data collection in 1985. Since the Northern Cheyenne have continuously inhabited the region since the battle occurred, there has been a continuity over time between the people, the landscape and the battle's mythology. A few of the emergent themes deal with Custer's previous relationship to the Cheyennes (he betrayed them as evidenced by smoking the peace pipe and then attacking them); the "mechanics" of the battle (the Indians were not surprised and in fact laid a trap for Custer); the reasons for the 7th Cavalry's loss (the soldiers were drunk, incompetent, or poorly led); Custer's aspirations (he would get to be president if he wiped out the Cheyennes); and the lack of interest on the part of the contemporary Cheyennes (Why are the whites still preoccupied with this event?). Many Cheyenne approve of the manner in which the National Park Service is telling the Custer story at the battlefield, but some say that there should be a monument to the Indians who fell there. Some noted that there is an Indian view of the battle and a white perspective and that the Park Service stresses the latter too much. A belief that the Crows have inappropriately profited from the Custer phenomenon was expressed by some informants.

\section{Remaining Work}

With the completion of transcription for the two remaining interviews, a final report will be prepared; the completion date is no later than March 31, 1987. The first two chapters-introduction and methodology-have already been prepared. The final section will contain an analysis of themes, summary of findings and recommendations for the oral history program at Custer Battlefield. Copies of 27 cassette tapes, representing the total data collected for this research project, have already been submitted to the library of Dull Knife Memorial College in Lame Deer, Montana. This is in compliance with a cooperative agreement between the investigator and that institution, which was implemented in 1985 at the outset of this research program. Also anticipated in the near future is the preparation, in conjunction with the librarian of Dull Knife College, of an oral history guide. 


\section{Conclusions}

The preliminary findings indicate that there is a body of orally-derived and transmitted knowledge about the Battle of Iittle Bighorn, which has been passed on from generation to generation. Although the specifics of the battle have been somewhat blurred with the passage of time, there continues to be some consistent themes regarding this extraordinary event and its relationship to the contemporary people and places of the Little Bighorn region. While the battle continues to be indelibly stamped in the cheyenne consciousness, it increasingly lacks relevance for succeeding generations of Cheyenne youth. 